\title{
Long-term stability of adolescent versus adult surgery for treatment of mandibular deficiency
}

\author{
William R. Proffit, Ceib Phillips, and Timothy A. Turvey \\ Departments of Orthodontics and Oral-Maxillofacial Surgery, School of Dentistry, University of \\ North Carolina, Chapel Hill, NC, USA
}

\begin{abstract}
In mandibular deficient patients, mandibular growth is not expected after the adolescent growth spurt, so mandibular advancement surgery is often carried out at 13 years. To test if the long-term stability for younger patients is similar to that for adult patients, the authors compared cephalometric changes from 1 year postsurgery (when changes due to the surgery should be completed) to 5 year follow up. 32 patients who had early mandibular advancement with or without simultaneous maxillary surgery (aged up to 16 for girls and 18 for boys), and 52 patients with similar surgery at older ages were studied. Beyond 1 year postsurgery, the younger patients showed significantly greater change in the horizontal and vertical position of points B and pogonion, the horizontal (but not vertical) position of gonion, and mandibular plane angle. 50\% of younger patients had 2-4 mm backward movement of Pg and another $25 \%$ had $>4 \mathrm{~mm}$. $15 \%$ of older patients had $2-4 \mathrm{~mm}$ change and none had $>4 \mathrm{~mm}$. Long-term changes in younger patients who had 2-jaw surgery were greater than for mandibular advancement only. Changes in younger groups were greater than for adult groups. Satisfaction with treatment and perception of problems were similar for both groups.
\end{abstract}

\section{Keywords}

stability; adolescent; adult; surgery; mandibular deficiency

The timing of surgical treatment for younger patients with mandibular deficiency is guided by two considerations. The first is that studies of patients who had mandibular advancement prior to the adolescent growth spurt show little or no forward growth of the mandible after surgery, although vertical growth of the mandible does occur so that downward-backward rotation of the mandible is avoided.16 The second is that late forward mandibular growth almost never occurs in mandibular deficient patients, as often is the case in patients with mandibular prognathism.11 Based on this, it seems logical to wait to advance the mandible surgically until after the adolescent growth spurt, except in exceptional situations (for example, severe deficiency leading to sleep apnea or extreme social problems) and in

\footnotetext{
(C) 2010 International Association of Oral and Maxillofacial Surgeons. Published by Elsevier Ltd. All rights reserved. *corresponding author: William_Proffit@dentistry.unc.edu; 919-966-4428, Departments of Orthodontics and Oral-Maxillofacial Surgery, School of Dentistry, University of North Carolina, Chapel Hill, NC 27599-7450.

Publisher's Disclaimer: This is a PDF file of an unedited manuscript that has been accepted for publication. As a service to our customers we are providing this early version of the manuscript. The manuscript will undergo copyediting, typesetting, and review of the resulting proof before it is published in its final citable form. Please note that during the production process errors may be discovered which could affect the content, and all legal disclaimers that apply to the journal pertain.

Declarations

Competing Interests: None

Ethical Approval: N/A
} 
patients who want treatment as soon as possible when the growth spurt is completed or nearly completed. ${ }^{12}$ No comparison of long-term changes in patients selected in this way for early surgery with those in older patients has been reported. The objective of this study was to compare long-term changes (from 1 year to 5 years or more postsurgery) in patients with mandibular advancement as soon as growth had apparently stopped with those who had surgical advancement as adults.

\section{Methods}

As of March 2009, the data base of the Dentofacial Program at the authors' institution contained complete records, including 5-year or longer recall, for 32 patients who had mandibular advancement with or without simultaneous maxillary surgery at the age of 16 years or younger for girls and 18 years or younger for boys. Cephalometric changes and psychosocial data for these younger patients were compared with data from 52 older patients who had mandibular advancement at 17 years of age or older for girls and 19 years or more for boys. All these patients had rigid internal fixation. Demographic and pre-treatment characteristics of the sample are shown in Table 1. The percentage of patients with 2-jaw surgery was higher in the younger group and the severity of the skeletal discrepancy was greater in both the 2-jaw and mandible only younger patients. Since early surgery is primarily carried out for patients with strong social concerns who want surgery as soon as possible, this difference reflects a degree of selection for severe problems in the younger group.

The lateral cephalometric radiographs were digitized using the UNC 130-point model. ${ }^{15}$ Changes in landmark position and dimensions from 1 to 5 years postsurgery were calculated. For cephalometric changes, the data were evaluated from two perspectives: the mean changes and the percentage of patients with significant clinical change. Analysis of covariance with alpha set at 0.01 was used to compare the change between the two groups from 1 to 5 years, controlling for the 1 year postsurgery values.

A subset of patients in both groups also completed treatment satisfaction (SAT) and longterm condition-specific quality of life questionnaires: problems with occlusion and function (PSPOF), problem perceptions (PSP), and problems with facial sensation (PFS). The questionnaires were developed, refined and the subscale structure identified by factor analysis as part of the preliminary aspects of NIH grant DE10028, Psychosocial vs Clinical Outcomes of Orthognathic Surgery. The questionnaires have been used in multiple projects and the directionality of response over time and between treatment groups has been consistent with the theoretical framework. ${ }^{9}, 10$ Each of the questionnaires has subscales related to specific aspects of the index. With alpha set at 0.01 , unpaired $t$ tests were used to compare the average value rating for each subscale of the two groups.

\section{Results}

Mean and standard deviations for changes in landmark positions and dimensions from 1 year postsurgery to 5 years or longer in the two groups are shown in Table 2, and the percentage of patients with changes is illustrated in Figure 1-Figure 3.

Between 1 and $>5$ years postsurgery, the long-term posterior movement of points B, pogonion $(\mathrm{Pg})$ and gonion $(\mathrm{Gn})$ was significantly greater in the younger patients than in the older ones, with the greatest difference at pogonion (mean change $-3 \mathrm{~mm}$ for the younger patients, $-0.3 \mathrm{~mm}$ for the older ones, $\mathrm{P}<0.0001$ ) (Table 2). In both groups, only small horizontal changes at condylion $(\mathrm{Co})$ were noted and this difference was not significant. 
Slightly more than half of the younger group had 2-4 mm backward movement of pogonion from 1 to $>5$ years postsurgery, and another $25 \%$ had $>4 \mathrm{~mm}$ backward movement, as opposed to $15 \%$ with $2-4 \mathrm{~mm}$ and none with $>4 \mathrm{~mm}$ in the older patients (Fig. 1). The percentage of patients with horizontal changes at gonion was smaller in both groups but the relative difference in percentages for the two groups was similar. Changes at condylion occurred in a minority of the patients in both groups, with an almost identical pattern of change.

Statistically significant differences in vertical landmark positions were noted only for points $\mathrm{B}$ and pogonion (Table 2). In the younger group, if the vertical position of pogonion changed, it was much more likely to move up and $15 \%$ had a $>4 \mathrm{~mm}$ upward movement (Fig 2). In the older group upward and downward changes were equally likely, and only $4 \%$ had a $>4 \mathrm{~mm}$ upward movement. In both groups, changes at gonion occurred in over half the patients, with downward movement predominating, and the pattern was almost identical. At condylion, older patients who had a $2 \mathrm{~mm}$ or more change were as likely to have upward as downward movement. In the younger group, none had 2-4 mm upward change while $25 \%$ had $>4 \mathrm{~mm}$ downward movement.

The only statistically significant difference in dimensional changes between the two groups was for the mandibular plane angle (Table 2). Most of those in the older group who had a change showed a decrease in this angle, while in the younger group most of those with change had an increase (Fig 3). Overjet increased $2-4 \mathrm{~mm}$ in about $20 \%$ of both groups. Mandibular length ( $\mathrm{Co}-\mathrm{Pg}$ ) changed in nearly twice as many older as younger patients, but in both groups the chance of an increase was about equal to the chance of a decrease. A higher percentage of older patients also had a change in ramus height (Co-Gn).

Scores on the psychosocial indices, including the subscales for each index, are shown in Table 3. For SAT, a higher score indicates greater satisfaction (and therefore is good); for the other indices a higher score indicates more problems (and therefore is bad).

There were no statistically significant differences between the two groups (Table 3). Only two items even came close to significance: satisfaction in the context of interpersonal outcomes; and problems with altered functional sensation. Despite their greater long-term cephalometric changes, the younger group tended to report higher satisfaction and fewer problems.

\section{Discussion}

The literature contains numerous papers on the outcome of sagittal split osteotomy to advance the mandible, ${ }^{5}$ but there are few reports of changes between 1 and 5 years postsurgery. Although it seems reasonable to expect that surgical healing would be complete at 1 year, the authors have previously reported that cephalometric changes in orthognathic surgery patients continue into the period $2-5$ years postsurgery, with minimal change beyond that. ${ }^{6,12,15}$ Cephalometric changes are seen over a 5-year time period in untreated adults and in adults treated with orthodontics alone, ${ }^{7,14}$ but the average amount of long-term change in surgical patients is larger. ${ }^{11}$ Mobarak et al reported a larger change in the position of pogonion at 3 years that was high relative to previously reported changes at 1 or 2 years, ${ }^{8}$ and the amount of change seen at 5 years appears to be greater. Changes beyond 1 year represent some combination of postural change, compensatory bone remodeling, dental changes and late growth in the pattern that produced the original dentofacial deformity. These long-term changes are probably minimally related to the type of surgery, the type of surgical fixation, and other influences on stability that affect changes during the first year. 
In this study, patients who had mandibular advancement prior to the end of adolescence had more long-term change than those who had surgery later, especially in the antero-posterior and vertical position of the chin, and the pattern of change was different. The younger patients had a strong tendency for chin prominence to decrease. In the older patients, forward movement of the chin long-term was more likely although changes in both directions were observed.

It is important to keep in mind that more of younger patients had maxillary as well as mandibular surgery (superior repositioning of the maxilla in all cases), and that the younger patients had larger maxillo-mandibular discrepancies than the older ones (Table 1). A comparison of the younger patients who had 2-jaw surgery with those who had mandibular surgery alone (Table 4) shows that the cephalometric changes between 1 and 5 years were similar. In the 2-jaw group there was slightly more vertical change than in the 1-jaw group, but this difference is not nearly large enough to account for the difference between the younger and older patients. At the time of surgery, the amount of mandibular advancement was similar in the groups with 2-jaw and mandibular surgery (Table 1). It appears that the long-term changes were not just a function of the type of surgery or the original skeletal pattern.

Another possible explanation for the difference in skeletal change would be more condylar remodeling in the younger patients that led to a greater decrease in mandibular length, but changes in the Co-Pg and Co-Gn distances were similar in the two groups (Fig 2).

Movement at condylion was variable in the older patients who had at least $2 \mathrm{~mm}$ of change, while in the younger group, when movement occurred it was downward and backward. The mandibular plane angle almost always increased when it changed in the younger patients and decreased when it changed in most of the older ones (Fig 3). Both of these findings suggest that late vertical growth, in the younger patients who had only mandibular surgery as well as in the 2-jaw patients, contributed to the changes at pogonion.

The authors have observed previously that changes in skeletal landmark positions tend to be greater than changes in tooth position and occlusal relationships. This dental compensation for skeletal change occurred in both groups, but particularly in the younger patients. On average (Table 2), in the younger group the lower molar moved back $1.3 \mathrm{~mm}$ while points $B$ and pogonion moved back $2.5 \mathrm{~mm}$ and $3 \mathrm{~mm}$, respectively, and overjet increased by only 1 $\mathrm{mm}$.

Following surgical correction of Class III problems $\{\mathrm{AQ} 1\}$, stability is not as good as for Class II patients during the first postsurgical year, but the Class II patients have more change beyond 1 year than the Class III group. ${ }^{3,6,13}$ The guideline for surgical Class III patients has been to wait until mandibular growth stops or almost stops at the end of adolescence. The authors' recent report documents that long-term stability for the patients selected for early surgical treatment is the same as those who had later surgery. ${ }^{2}$ It is not obvious why longterm changes are more likely in the adolescent Class II group, but this information should be made available to patients as part of informed consent for treatment.

The greater long-term postsurgical change in the younger patients was not reflected in their degree of satisfaction with treatment or perception of problems related to recovery from surgery or the treatment outcome. None of the patients in either group were re-treated for unacceptable relapse. Both the younger and older patients reported a relatively high degree of satisfaction with treatment and relatively low perception of problems. Although no differences were statistically significant, the younger patients were slightly more positive on almost all the indices. From the patient's perspective, it appears that early mandibular 
advancement is as successful as later advancement despite the unexpected finding of poorer long-term stability.

\section{Acknowledgments}

The authors thank Debora Price for data base analysis and production of the graphs illustrating long-term change.

Funding: This work was supported in part by NIH grant DE05215 from the National Institute of Dental and Craniofacial Research.

\section{References}

1. Bailey LJ, Duong HL, Proffit WR. Surgical Class III treatment: long-term stability and patient perceptions of treatment outcome. Int J Adult Orthod Orthogn Surg 1998;13:35-44.

2. Bailey LJ, Phillips C, Proffit WR. Long-term outcome of surgical Class III correction as a function of age at surgery. Am J Orthod Dentofac Orthop 2008;133:365-370.

3. Busby BR, Bailey LJ, Proffit WR, Phillips C, White RP. Long-term stability of surgical Class III treatment: a study of 5-year postsurgical results. Int J Adult Orthod Orthogn Surg 2002;17:159-170.

4. Joss CU, Thuer UW. Stability of the hard and soft tissue profiles after mandibular advancement with sagittal split osteotomies: a longitudinal and long-term follow-up study. Eur J Orthod 2008;30:1623. [PubMed: 17962316]

5. Joss CU, Vassalli IM. Stability after bilateral sagittal split osteotomy advancement surgery with rigid internal fixation: a systematic review. Am J Oral Maxillofac Surg 2009;67:301-313.

6. Miguel JA, Turvey TA, Phillips C, Proffit WR. Long-term stability of two-jaw surgery for treatment of mandibular deficiency and vertical maxillary excess. Int. J Adult Orthod Orthogn Surg 1995;10:235-245.

7. Mihalik CA, Proffit WR, Phillips C. Long-term follow-up of Class II adults treated with orthodontic camouflage: a comparison with orthognathic surgery outcomes. Am J Orthod Dentofac Orthop 2003;123:266-278.

8. Mobarak JA, Espeland L, Krogstad O, et al. Mandibular advancement surgery in high-angle and low-angle Class II patients: different long-term skeletal responses. Am J Orthod Dentofac Orthop 2001;119:368-381.

9. Phillips C. Patient-centered outcomes: impact on clinical practice and research. Sem Orthod 1999;5:223-231.

10. Phillips, C.; Bennett, ME. Psychological ramifications of orthognathic surgery. In: Betts, NJ.; Turvey, TA., editors. Oral and Maxillofacial Surgery. Vol. vol 2. Philadelphia: WB Saunders Co; 2000. p. 527-530.

11. Proffit WR, Phillips C, Tulloch JFC, Medland PH. Orthognathic vs orthodontic correction of skeletal Class II malocclusion in adolescents: effects and indications. Int J Adult Orthod Orthogn Surg 1992;7:209-220.

12. Proffit, WR.; Phillips, C. Physiologic response to treatment and postsurgical stability. In: Proffit, WR.; White, RP.; Sarver, DM., editors. Contemporary Treatment of Dentofacial Deformity. St Louis: CV Mosby Co; 2003.

13. Proffit WR, Phillips C, Turvey TA. The hierarchy of stability and predictability in orthognathic surgery: an update and extension. Head Face Med. 2007 3:21. [online at www.head-facemed.com]. [PubMed: 17470277]

14. Schubert P, Bailey LJ, White RP, Proffit WR. Long-term cephalometric changes in untreated adults compared to those treated with orthognathic surgery. Int J Adult Orthod Orthog Surg 1999;14:91-99.

15. Simmons KE, Turvey TA, Phillips C, Proffit WR. Surgical-orthodontic correction of mandibular deficiency: five year follow-up. Int J Adult Orthod Orthogn Surg 1992;7:67-80.

16. Snow MD, Turvey TA, Walker D, Proffit WR. Surgical mandibular advancement in adolescents: postsurgical growth related to stability. Int J Adult Orthod Orthognath Surg 1991;6:143-154. 
One Year Postsurg to Five Years

Horizontal Changes

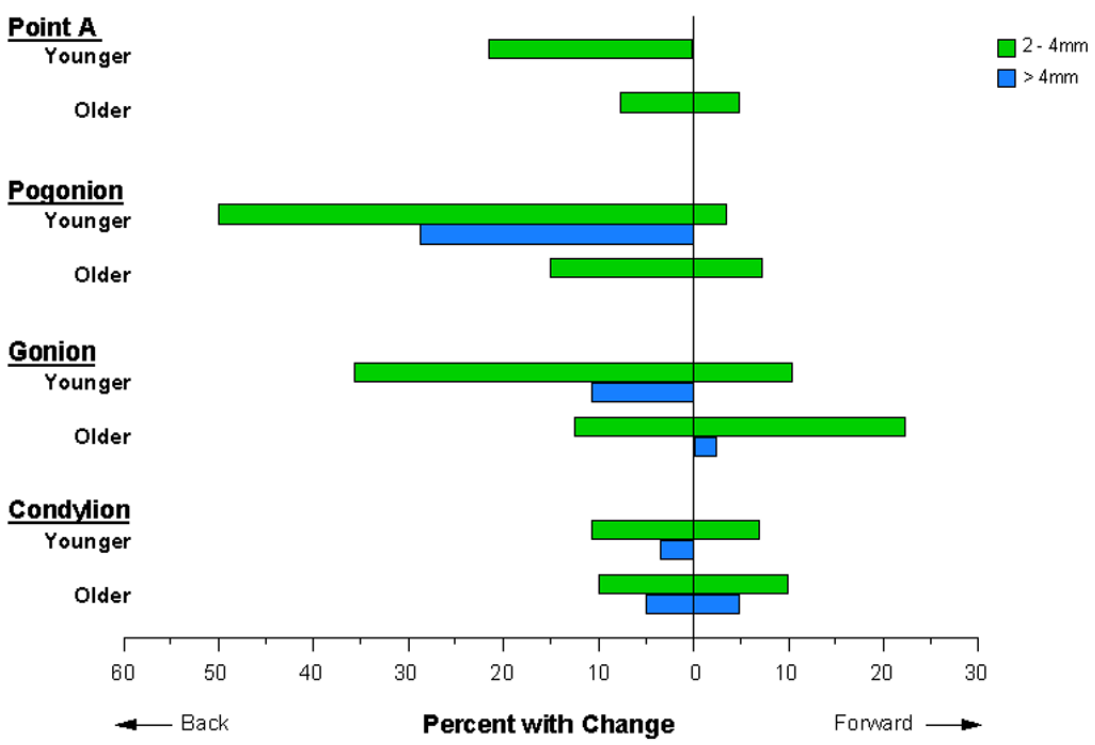

Figure 1.

Percentage of patients with horizontal changes in landmark positions, 1 year postsurgery to 5 years or longer. 


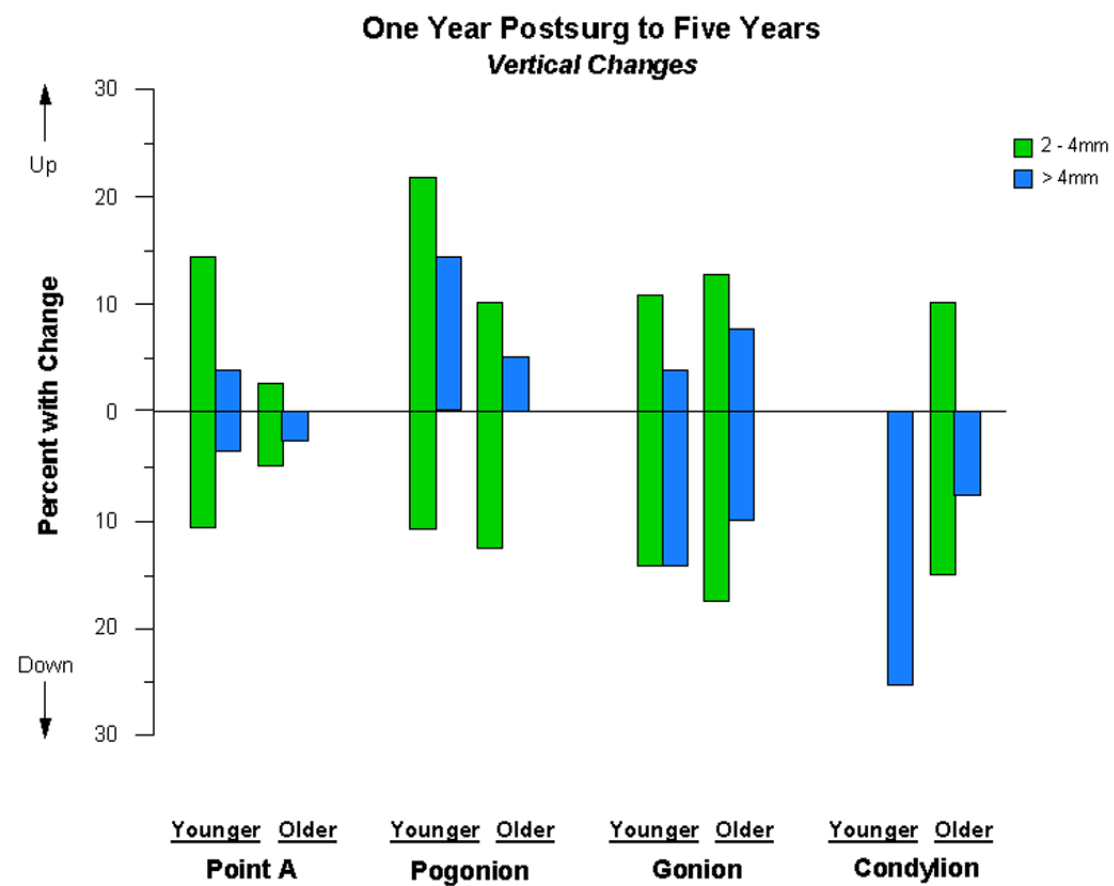

Figure 2.

Percentage of patients with vertical changes in landmark positions, 1 year postsurgery to 5 years or longer. 
One Year Postsurg to Five Years

Dimensional Changes

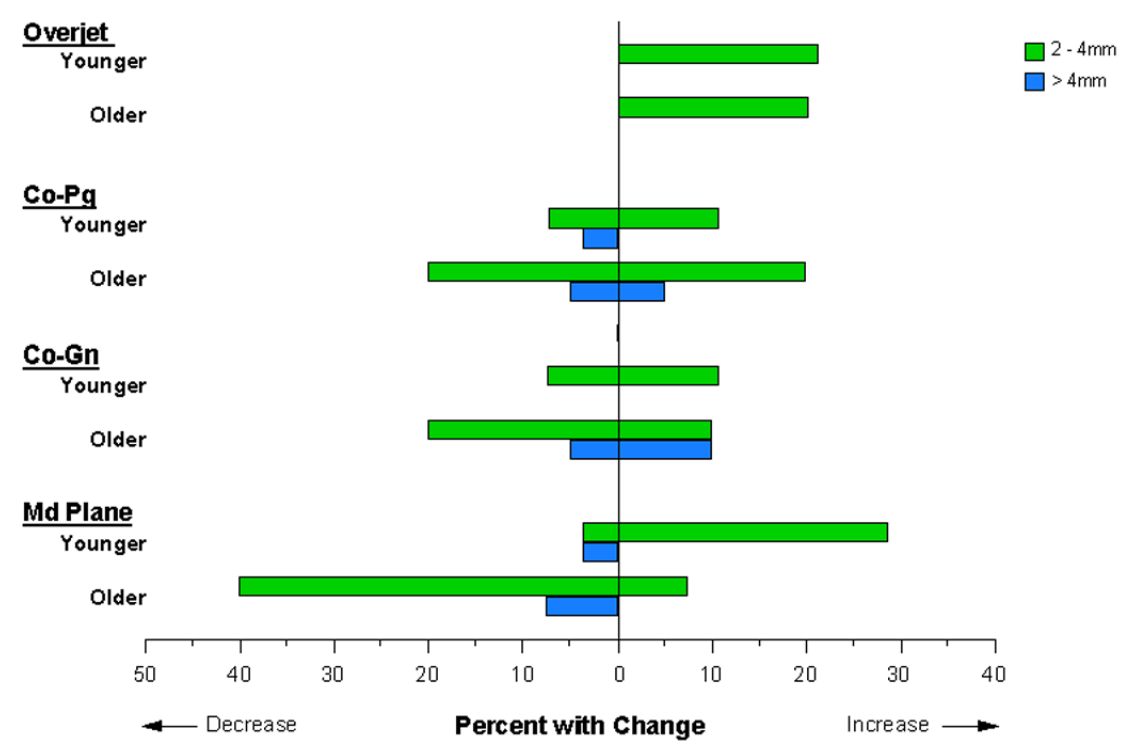

Figure 3.

Percentage of patients with changes in overjet, mandibular length (Co-Pg) and ramus height $(\mathrm{Co}-\mathrm{Pg})(\mathrm{mm})$ and mandibular plane angle (degrees), 1 year postsurgery to 5 years or longer. 


\section{TABLE 1}

Demographic and pre-treatment characteristics.

\begin{tabular}{lcc}
\hline & Younger & Older \\
Gender & $\mathbf{n = 3 2}$ & $\mathbf{n = 5 2}$ \\
Male & & \\
Female & $11(34 \%)$ & $12(23 \%)$ \\
Pretreatment & $21(66 \%)$ & $40(77 \%)$ \\
ANB $\left(^{\circ}\right)$ & & \\
Co-Pg (mm) & $6.7 \pm 2.4$ & $5.9 \pm 2.2$ \\
GoGn-SN $\left(^{\circ}\right)$ & $113.3 \pm 8.3$ & $115.0 \pm 7.4$ \\
N-Me (mm) & $37.9 \pm 10.5$ & $32.6 \pm 8.2$ \\
Surgery type & $126.1 \pm 9.7$ & $121.7 \pm 8.9$ \\
Mn advance only & $16(50 \%)$ & $44(85 \%)$ \\
Mn adv + Mx up & $16(50 \%)$ & $8(15 \%)$ \\
Age at surgery (years) & $15.9 \pm 1.7$ & $34.9 \pm 9.6$ \\
Male (range) & $16-19$ & $20-46$ \\
Female (range) & $13-17$ & $19-54$ \\
Surgery changes & & \\
Genioplasty also & $16(50.0 \%)$ & $8(15.4 \%)$ \\
Co-Pg (mm) & $7.1 \pm 3.4$ & $5.7 \pm 2.8$ \\
Change in Pg position & & \\
Horizontal (mm) & $8.2 \pm 5.8$ & $4.8 \pm 4.1$ \\
Vertical (mm) & $1.0 \pm 5.9$ & $3.8 \pm 2.8$ \\
GoGn-SN change $\left({ }^{\circ}\right)$ & $-3.1 \pm 5.5$ & $0.5 \pm 3.5$ \\
Follow-up (years) & $6.8 \pm 2.6$ & $6.9 \pm 3.0$ \\
Range & $4.5-14.9$ & $4.8-20.2$ \\
\hline
\end{tabular}

$\mathrm{Mx}=$ maxilla $; \mathrm{Mn}=$ mandible $; \mathrm{adv}=$ advance 


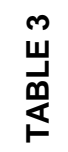


TABLE 4

Cephalometric comparison of 2-jaw versus mandibular surgery in young patients.

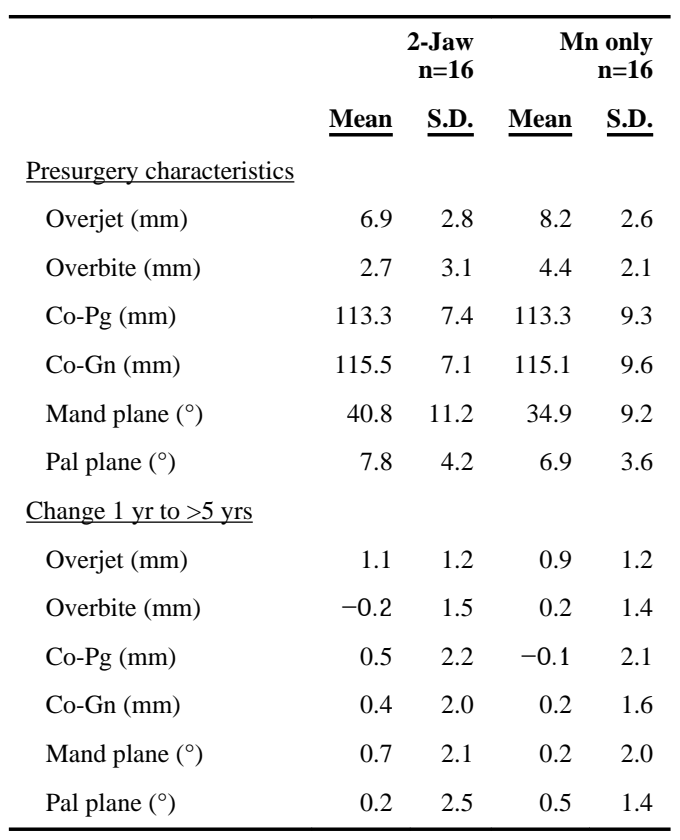

